\title{
Higher whole-blood selenium is associated with improved immune responses in footrot-affected sheep
}

\author{
Jean A Hall ${ }^{1 *}$, Rachel L Sendek1', Rachel M Chinn', D Paul Bailey ${ }^{1}$, Katie N Thonstad ${ }^{1}$, Yongqiang Wang²,
} Neil E Forsberg ${ }^{2}$, William R Vorachek', Bernadette V Stang ${ }^{3}$, Robert J Van Saun ${ }^{4}$ and Gerd Bobe ${ }^{2,5}$

\begin{abstract}
We reported previously that sheep affected with footrot (FR) have lower whole-blood selenium (WB-Se) concentrations and that parenteral Se-supplementation in conjunction with routine control practices accelerates recovery from FR. The purpose of this follow-up study was to investigate the mechanisms by which Se facilitates recovery from FR. Sheep affected with FR $(n=38)$ were injected monthly for 15 months with either 5 mg Se (FR$\mathrm{Se}$ ) or saline (FR-Sal), whereas 19 healthy sheep received no treatment. Adaptive immune function was evaluated after 3 months of Se supplementation by immunizing all sheep with a novel protein, keyhole limpet hemocyanin $(\mathrm{KLH})$. The antibody titer and delayed-type hypersensitivity (DTH) skin test to KLH were used to assess humoral immunity and cell-mediated immunity, respectively. Innate immunity was evaluated after 3 months of Se supplementation by measuring intradermal responses to histamine 30 min after injection compared to KLH and saline, and after 15 months of Se supplementation by isolating neutrophils and measuring their bacterial killing ability and relative abundance of mRNA for genes associated with neutrophil migration. Compared to healthy sheep, immune responses to a novel protein were suppressed in FR-affected sheep with smaller decreases in FRaffected sheep that received Se or had WB-Se concentrations above $250 \mathrm{ng} / \mathrm{mL}$ at the time of the immune assays. Neutrophil function was suppressed in FR-affected sheep, but was not changed by Se supplementation or WB-Se status. Sheep FR is associated with depressed immune responses to a novel protein, which may be partly restored by improving WB-Se status (> $250 \mathrm{ng} / \mathrm{mL}$ ).
\end{abstract}

\section{Introduction}

Footrot (FR) is a common, contagious bacterial disease of sheep that results in lameness and large production losses for the sheep industry. Footrot is caused by infection with the bacterium Dichelobacter nodosus, a gramnegative, anaerobic and fastidious bacterium, in association with other bacteria, particularly Fusobacterium necrophorum [1-3]. When the interdigital skin of the foot is damaged or wet for a prolonged period of time, it may become invaded by the ubiquitous soil and fecal bacterium $F$. necrophorum. F. necrophorum causes interdigital dermatitis and produces toxins that cause necrosis of the superficial layer of the skin allowing co-

\footnotetext{
* Correspondence: Jean.Hall@oregonstate.edu

'Department of Biomedical Sciences, College of Veterinary Medicine, Oregon

State University, Corvallis, OR 97331-4802, USA

Full list of author information is available at the end of the article
}

infection with other bacteria such as D. nodosus. D. nodosus contains surface fimbriae and stable extracellular proteases that allow it to colonize the interdigital epithelial tissue, digesting the living dermis, and feeding on collagen $[4,5]$. A foul smell is associated with the accumulation of grey pasty exudate between the dermis and epidermal horn, and ultimately separation of the hoof horn from the underlying dermis occurs [5]. Although a program that requires strict culling during the hot, dry summer months (non-transmission period) has proven successful in eliminating FR in flocks in Western Australia [6], this protocol is unfeasible in other countries with cool, wet climates and widespread prevalence of infected flocks [5]. In these situations, management programs to control rather than eliminate infection are more important. Strategies include parenteral antibiotic treatment, topical antibacterial sprays,
C Biomed Central

(c) 2011 Hall et al; licensee BioMed Central Ltd. This is an Open Access article distributed under the terms of the Creative Commons Attribution License (http://creativecommons.org/licenses/by/2.0), which permits unrestricted use, distribution, and reproduction in any medium, provided the original work is properly cited. 
trimming of horn hoof, vaccination, low stocking density, and genetic selection for sheep breeds less susceptible to FR $[5,7]$.

The role of the immune system in the etiology of FR is not well understood. Adaptive immunity, including humoral and cell mediated immunity (CMI), likely play a role in protection against FR $[8,9]$, yet infected or vaccinated sheep do not develop long-term immunity and may become re-infected over time $[5,10,11]$. T-cell antigen presentation may be biased between strains of $D$. nodosus because vaccination with a polyvalent serotype vaccine does not protect against all strains equally [8]. Heritability of resistance to FR may be related to a specific range of $\mathrm{MHC}$ II haplotype that is required to generate a sufficient immune response to $D$. nodosus [9].

We reported previously that FR-affected sheep have lower whole-blood selenium (WB-Se) concentrations and that parenteral Se-supplementation in conjunction with routine control practices accelerates recovery from FR [12]. As a follow-up, we examined in this study the mechanisms by which Se may facilitate recovery from FR. Selenium deficiency results in immunosuppression and inhibits resistance to bacterial and viral infections, neutrophil function, antibody production, proliferation of $\mathrm{T}$ and $\mathrm{B}$ lymphocytes in response to mitogens, and cytodestruction by $\mathrm{T}$ lymphocytes and NK cells [13]. It is unknown whether Se supplementation to Se-replete ewes can improve innate immunity of neutrophils (bacterial killing) or acquired immunity, including humoral and CMI, in FR-affected sheep. We hypothesized that Se functions as an immunonutrient, and enhances both arms of the immune response and, thereby, accelerates the recovery from FR. Because immune responsiveness in sheep with FR, and the ability of Se to alter immune responses to a foreign protein in sheep with FR are not well understood, we used a broad approach. We measured the antibody titer and performed a delayed-type hypersensitivity (DTH) skin test to a novel protein, keyhole limpet hemocyanin (KLH), to assess humoral and CMI, respectively, in healthy and FR-affected sheep. Innate immunity was evaluated by measuring an intradermal histamine response, and by isolating neutrophils and assessing bacterial killing ability and relative abundance of mRNA for genes associated with neutrophil migration.

\section{Materials and methods Animals and study design}

The animals and study design have been described in detail previously [12], including the WB-Se assay and foot scores. In short, this was a placebo-controlled clinical trial of 15-months duration involving crossbred, primarily black-faced mature ewes (age: 2-6 y; body weight: $100-110 \mathrm{~kg}$ ). A commercial sheep flock was chosen for the project based on a high incidence of FR and the owner's willingness to participate in a longterm clinical trial. At the beginning of the study, FRaffected ewes $(n=38$; the duration of FR in the sheep was unknown) were alternately randomized into two treatment groups and at 1-month intervals injected subcutaneously with $5 \mathrm{mg}$ of Se (FR-Se; sodium selenite containing $45.6 \%$ Se; MU-Se, ${ }^{\circledR}$ Schering-Plough Animal Health Corp., Union, NJ) or with $1 \mathrm{~mL}$ of saline solution (FR-Sal) for the duration of the study. A control group of healthy sheep without FR $(n=19)$ was also identified at the beginning of the study; they received no injections. Ear tags and paint brands were used to identify the ewes. Sheep feet were examined, trimmed, and scored for FR at 0, 3, 6, 9, and 15 months using a scale of 0 (no evidence of FR), 1 (interdigital dermatitis, presence of heat, and characteristic FR odor), 2 (initial underruning of the hoof wall between the toes), 3 (underrunning of the sole), and 4 (extensive underrunning of the sole and lateral walls of the hoof). The score of the foot with the highest lesion score was used for the statistical analysis. The experimental protocol was reviewed and approved by the Oregon State University Animal Care and Use Committee.

All sheep were fed primarily on pasture, except for a short period around lambing time in early winter when they were brought into the barn and fed hay silage. Routine farm management practices were not altered. A custom-made mineral supplement (Sonka Custom Mineral Premix, Wilbur-Ellis Company, Clackamas, OR, USA) that contained Se was provided free choice to all ewes throughout the duration of the study. The mineral supplement contained $5.0 \%$ calcium, $4.5 \%$ phosphorus, $40.0 \%$ salt $(\mathrm{NaCl}), 6.0 \%$ magnesium, $120 \mathrm{mg} / \mathrm{kg}$ cobalt, 4 $000 \mathrm{mg} / \mathrm{kg}$ manganese, $250 \mathrm{mg} / \mathrm{kg}$ iodine, $200 \mathrm{mg} / \mathrm{kg} \mathrm{Se}$, $5000 \mathrm{mg} / \mathrm{kg}$ zinc, 250000 I.U./lb vitamin A, $40000 \mathrm{I}$. U./lb vitamin D, and 200 I.U./lb vitamin E. The mineral supplement was intended to be diluted with salt to provide $90 \mathrm{mg} / \mathrm{kg}$ Se as per the FDA-regulations for freechoice minerals. Average consumption of the mineral mixture by the sheep in this trial was not determined. All sheep had equal access to the mineral product. However, as is typical of free-choice mineral products, there is significant individual variation in intake. Based on the mineral's salt content, expected daily intake would be between 5 and $10 \mathrm{~g} /$ head resulting in Se intake of $1-2 \mathrm{mg} / \mathrm{d}$, which is higher than the $0.7 \mathrm{mg} / \mathrm{d}$ $(0.7 \mathrm{mg} / \mathrm{d}$ is considered equivalent to $0.3 \mathrm{mg} / \mathrm{kg}$ supplemental Se in the total diet) allowed by the FDA. The FR control program in this flock consisted of a walkthrough formalin foot bath (used monthly or less often). A FR-vaccination program was not used. No antibiotics for FR treatment were administered. This program continued for all sheep for the duration of the study. 


\section{Delayed-type hypersensitivity (DTH) skin test with keyhole limpet hemocyanin (KLH)}

Adaptive immune function was evaluated after 3 months of Se supplementation by immunizing all sheep twice 2weeks apart with $0.5 \mathrm{~mL}$ of KLH $(500 \mu \mathrm{g}$ of KLH emulsified in $1.0 \mathrm{mg}$ of T1501 adjuvant for a total volume of $0.5 \mathrm{~mL}$; administered intramuscularly) as previously described [14]. One day after the second immunization, intradermal skin testing was performed. Swelling and induration following an intradermal challenge were measured in the DTH test to assess CMI response by $\mathrm{T}$ cells. Intradermal injections of KLH were administered in 2 wool-free sites on the ventro-lateral abdomen, and circled using a felt-tip marker, and on the ear tip (in only 40 of the 57 ewes because we had insufficient KLH). No chemical restraint was used. Separate intradermal injections of histamine and saline were administered on the ventro-lateral abdomen. Individual disposable tuberculin syringes were filled with heataggregated KLH; histamine base (0.1 g/L; Histatrol, Center Laboratories, Port Washington, NY, USA), a positive control; or saline $(0.9 \%)$, a negative control. A 25 -gauge needle was used to inject $0.05 \mathrm{~mL}$ of each of these intradermally. The $0.05-\mathrm{mL}$ dose of heat-aggregated KLH consisted of approximately $3 \mathrm{mg}$ of $\mathrm{KLH}$, and was prepared as described previously [14]. Measurements of wheal diameter and thickness (ear tip) were made at 0.5 , $24,48,72$, and $96 \mathrm{~h}$ after intradermal injections. The test was administered by the same person to all sheep. Reactions were recorded according to the diameter of induration and erythema. A reaction larger than the negative control was considered positive. If a positive reaction to the saline control was observed, its diameter was subtracted from the other reactions. After $24 \mathrm{~h}$, no reactions to the saline control were noted.

Innate immune function was evaluated 30 min after injection by measuring skin responses on the ventro-lateral abdomen to intradermal injections of histamine, $\mathrm{KLH}$, or saline. Histamine produced an induration typically larger than the saline control, after which the reaction subsided. Thus, these controls served also as tests of acute inflammation, in that any reaction larger than the saline reaction, which represented the volume of substance injected, was due to an acute inflammatory reaction.

\section{KLH antibody titer}

The KLH antibody titer was also used to assess adaptive immune function. The humoral immune response was evaluated after 3 months of Se supplementation by measuring the KLH antibody titer prior to the first $0.5 \mathrm{~mL}$ KLH immunization and 2 and 4 weeks after the second KLH immunization. Serum was assayed for KLH antibody titer by an indirect ELISA. Briefly, 96-well microtiter plates (Costar, Cambridge, MA, USA) were coated with $5 \mu \mathrm{g} / \mathrm{mL}$ of $\mathrm{KLH}(100 \mu \mathrm{L} /$ well; Sigma Chemical Co., St. Louis, MO, USA) in a $0.1 \mathrm{M}$ sodium bicarbonate buffer, sealed to prevent evaporation, and incubated at $4^{\circ} \mathrm{C}$ overnight. The next day the coating solution was removed and $100 \mu \mathrm{L}$ of StabilCoat (SurModics Inc., Eden Praire, MN, USA) was added to each well to block nonspecific binding sites and plates were incubated for $30 \mathrm{~min}$ at room temperature. After incubation, the StabilCoat was removed; plates were resealed and stored at $4{ }^{\circ} \mathrm{C}$ until used. Serum samples were serially diluted $(1: 100$ to $1: 1,024,000)$ in $0.05 \mathrm{M}$ PBS with $0.05 \%$ Tween-20 (T-PBS; pH 8.0). Each dilution was added to the plate in duplicate, and incubated for $30 \mathrm{~min}$ at room temperature. Positive and negative control serums were included on each plate. After incubation, plates were washed eight times with T-PBS and then $100 \mu \mathrm{L}$ of horseradish peroxidase conjugated to rec-Protein G (Zymed Laboratories Inc., San Francisco, CA, USA) was added to each well at a previously determined dilution (1:20,000). Rec-Protein G binds to IgG immunoglobulin through their Fc regions and was used instead of an anti-species conjugate as it resulted in equivalent results with a stronger signal and less background. After another $30 \mathrm{~min}$ incubation at room temperature, plates were again washed with T-PBS and 100 $\mu \mathrm{L}$ of 1.6 $\mu \mathrm{M}$ ABTS $/ \mathrm{H}_{2} \mathrm{O}_{2}$ (2,2'-Azino-bis [3-ethylbenzthiazoline-6-sulfonic acid]; Sigma) in $0.1 \mathrm{M}$ citrate buffer ( $\mathrm{pH} 4.0)$ was added to all wells. Plates were incubated at room temperature in the dark and were read when a positive reference sample reached an OD of 1.0. The OD of each well at $405 \mathrm{~nm}$ was determined using a Bio-Tek EL312 microplate reader (Bio-Tek Instruments Inc., Winooski, VT, USA). The antibody titer was expressed as an endpoint titer for each sample, which was calculated from a regression line of OD against sample dilution, with a threshold of 0.200 OD (approximately 3 times the OD generated by the background), using a software program (KinetiCalc, Bio-Tek Instruments Inc., Winooski, VT, USA).

\section{Neutrophil bacterial killing of Lactococcus lactis}

Bacterial killing by neutrophils was assessed after 15 months of Se supplementation. Neutrophils were isolated using a Percoll gradient technique [15], resuspended in Hank's balanced saline solution (HBSS) plus 0.5\% FBS, and counted using a Coulter counter. Briefly, $10 \mathrm{~mL}$ of heparinized blood was collected via jugular puncture, transported on ice to the lab, transferred into $50 \mathrm{~mL}$ tubes, and centrifuged at $1000 \times g$ for $20 \mathrm{~min}$ at $4{ }^{\circ} \mathrm{C}$ in a swinging bucket centrifuge to separate plasma and buffy coats from the red cell pack. Plasma, buffy coat and one-third of the red cell pack from each tube were aspirated aseptically and discarded. The remaining 
red cell packs containing neutrophils were mixed with $34 \mathrm{~mL}$ of ice-cold PBS. Samples were layered onto 10 $\mathrm{mL}$ of $1.084 \mathrm{~g} / \mathrm{mL}$ Percoll (Sigma Chemical Company, St. Louis, MO, USA), then centrifuged at $400 \times g$ for 40 min at $22{ }^{\circ} \mathrm{C}$. After centrifugation, the red blood cells (RBC) and neutrophils pelleted at the bottom of the tube and the mononuclear cell band remained at the sample/medium interface. Supernatant, mononuclear cell layer and Percoll were aspirated and discarded. Red blood cells were lysed using $24 \mathrm{~mL}$ ice-cold hypotonic lysing solution (10.56 mM Na $\mathrm{HPO}_{4}, 2.67 \mathrm{mM}$ $\mathrm{NaH}_{2} \mathrm{PO}_{4}, \mathrm{pH} 7.3$ ) for $90 \mathrm{~s}$. Isotonicity was restored by adding $12 \mathrm{~mL}$ ice-cold hypertonic restoring solution (10.56 mM Na $2 \mathrm{HPO}_{4}, 2.67 \mathrm{mM} \mathrm{NaH} \mathrm{PO}_{4}, 0.43 \mathrm{M}$ $\mathrm{NaCl}, \mathrm{pH}$ 7.3). Remaining leukocytes were pelleted by centrifugation at $800 \times g$ for $5 \mathrm{~min}$ at $4{ }^{\circ} \mathrm{C}$. A $20 \mu \mathrm{L}$ aliquot of the cell suspension was used to determine cell concentration (Coulter ZB1 Counter, Coulter Electronics Inc., Hialeah, FL, USA). Another $5 \mu \mathrm{L}$ aliquot was used to assess purity of neutrophil preparations (differential cell count) by microscopic examination after Wright-Giemsa staining (95 $\pm 1 \%$; mean \pm SEM).

Neutrophils $\left(2 \times 10^{5}\right.$ cells/well $)$ were seeded into triplicate wells of a 96-well tissue culture plate, previously coated with poly-D-lysine. Neutrophils were activated for 10 min with $25 \mathrm{nM}$ PMA (diluted in DMSO; < $1 \%$ final solution). Logarithmic phase Lactococcus lactis (MG1363) bacteria containing an erythromycin-resistant plasmid were grown in M17 + glucose (M17G) + erythromycin media and diluted to the desired concentration in RPMI media $+2 \%$ heat-inactivated sheep serum (Biomeda, Burlingame, CA, USA). Bacteria were added to the neutrophils at a multiplicity of infection (MOI) of 0.01 . After $1 \mathrm{~h}$ incubation at $37{ }^{\circ} \mathrm{C}$ in $5 \% \mathrm{CO}_{2}$, media in the wells containing neutrophils and bacteria was serially diluted and plated onto M17G medium containing erythromycin for overnight incubation and enumeration of colony forming units (CFU). Internal control wells without neutrophils were used to determine baseline bacterial counts at the assay endpoints. Percent survival of bacteria was calculated as $[(\mathrm{CFU} / \mathrm{mL}$ experimental well $) /(\mathrm{CFU} / \mathrm{mL}$ control well $)] \times 100 \%$.

\section{Relative abundance of selected mRNAs specific for neutrophil migration (L-selectin, IL-8R)}

Gene expression by neutrophils was evaluated after 15 months of Se supplementation. Neutrophils were isolated as described above and frozen at $-80{ }^{\circ} \mathrm{C}$. Total RNA was extracted following manufacturer's instructions using a RNeasy ${ }^{\circledR}$ Mini Kit (Qiagen Sciences; Germantown, MD, USA), quantified using the ND-1000 NanoDrop Spectrophotometer (Thermo Fisher Scientific; Waltham, MA, USA), and stored at $-80{ }^{\circ} \mathrm{C}$. Aliquots of $500 \mathrm{ng}$ RNA in $10 \mu \mathrm{L}$ were used for RT-qPCR.
Relative mRNA abundance were determined for L-selectin and IL-8R to evaluate gene expression of markers involved in neutrophil migration, adherence, and activation using the Taqman ${ }^{\circledR}$ One-Step RT-PCR Master kit (Applied Biosystems, Branchburg, NJ, USA). Levels of ribosomal protein large subunit family member (RPL19) mRNA were measured to normalize selected mRNA. Results were expressed as fold change using the relative quantification method of Pfaffl [16]. The abundance of target genes, normalized to RPL-19 (as the internal control) and relative to the control group of sheep, were illustrated by $2^{-\Delta \Delta C t}$, where $C t$ was the cycle number at which the fluorescence signal of the product crossed an arbitrary threshold set with exponential phase of the PCR and $\Delta \Delta \mathrm{Ct}=\left(\mathrm{Ct}_{\text {target gene unknown sample }}\right.$ - $\left.C t_{\text {RPL-19 unknown sample }}\right)$ - $\left(\mathrm{Ct}_{\text {target gene calibrator sample - }}\right.$ $\mathrm{Ct}_{\mathrm{RPL}-19 \text { calibrator sample). }}$.

The RT-qPCR oligonucleotide primers for these genes of interest are proprietary (OmniGen Research LLC, Canby, OR, USA) and were designed based on bovine DNA sequence data. To verify that these primers were amplifying sheep cDNA, RT-qPCR primers were used to amplify sheep genomic DNA. The products were run on a $2 \%$ agarose gel and the approximately 125 base-pair band was excised. The DNA fragment size was confirmed using a 50 base pair ladder, and selected bands were excised and purified from the agarose gel using a QIAquick Gel Extraction Kit (QIAGEN Inc., Germantown, MD, USA) according to manufacturer's instructions, and prepared for sequencing. Purified products were sequenced at the Oregon State University Center for Genome Research and Biocomputing (CORE Lab) using a DNA sequencer machine. Sequence analysis was performed using commercial software. The sequence obtained was used in a BLAST (National Center for Biotechnology Information, U.S. National Library of Medicine, Bethesda, MD, USA) search of all known mammalian genomic sequences. The search showed 96\% sequence identity to bovine IL-8R alpha and 99\% sequence identity to bovine SELL (aliases: CD62 antigen-like family member L; L-selectin; LAM-1; LECAM1; leukocyte adhesion molecule 1; leukocyte-endothelial cell adhesion molecule 1; lymph node homing receptor; lymphocyte adhesion molecule 1 ; selectin L), the most closely related species.

\section{Statistical analysis}

Statistical analyses were performed using SAS, version 9.2 (SAS, Inc., Cary, NC, USA) software. Antibody titers for KLH were normalized by $\log _{2}$ transformation and are shown as such. Relative mRNA abundance were analyzed using the internal standard-adjusted $\mathrm{Ct}$-values $\left(\mathrm{Ct}_{\text {target gene unknown sample }}-\mathrm{Ct}_{\mathrm{RPL}-19}\right.$ unknown sample $)$. Indicators of innate and adaptive immunity were analyzed 
using single (PROC GLM) and repeated measure analysis in time (PROC MIXED), respectively. Selenium treatment (healthy, FR-Se, FR-Sal) or Se-status at the time of the immune assays (healthy, FR-high Se, FR-low Se) were the covariates. Ages and production stage of ewes were not available for individual ewes in the commercial flock and thus, were not included in the model. Ewes were stratified by Se status because WB-Se concentrations of FR-Se and FR-Sal sheep overlapped (Table 1) [12]. The cut-off point for high and low Se was $250 \mathrm{ng} /$ $\mathrm{mL}$ Se in WB and was based on the median WB-Se concentration of FR-affected sheep at the time of the immune assays (3 and 15 months; [12]). For immune assays with multiple samples in time, time of sample collection and the interaction between time of sample collection and Se treatment or status were added as fixed effects. A completely unrestricted variance-covariance structure was used to account for repeated measures taken from individual ewes across time. To obtain the correct degrees of freedom, the KENWARDROGER option was invoked. The KENWARDROGER option consists of the Satterthwaite adjustment for degrees of freedom with a Kenward-Roger adjustment on standard errors, which can be used for repeated measures studies.

The effect of FR on indicators of immune function was evaluated by comparing the estimated values of the healthy group with those of the FR-affected groups. The effect of Se supplementation on indicators of immune function in FR-affected sheep was evaluated by comparing the estimated values of the FR-Se with those of the FR-Sal group. The effect of Se status on indicators of immune function in FR-affected sheep was evaluated by comparing the estimated values of the FR-high Se with those of the FR-low Se group. Data are reported as least square means \pm SEM. Statistical significance was declared at $P \leq 0.05$ and tendencies at $0.05<P \leq 0.15$.

Table 1 Whole-blood selenium concentrations in healthy and footrot (FR) affected sheep treated with selenium (FR-Se) or saline (FR-Sal)*

\begin{tabular}{lccc}
\hline & \multicolumn{2}{c}{ Median whole-blood Se (range); ng/mL } \\
\hline $\begin{array}{l}\text { Month of } \\
\text { Treatment }\end{array}$ & Healthy & FR-Se & FR-Sal \\
\hline 0 & $250(187351)^{\mathrm{a}}$ & $199(109278)^{\mathrm{b}}$ & $202(111323)^{\mathrm{b}}$ \\
3 & $245(145340)^{\mathrm{a}}$ & $261(189317)^{\mathrm{a}}$ & $199(110295)^{\mathrm{b}}$ \\
6 & $274(180396)^{\mathrm{b}}$ & $302(267403)^{\mathrm{a}}$ & $268(176408)^{\mathrm{b}}$ \\
15 & $230(165302)$ & $288(157416)$ & $237(104344)$ \\
\hline
\end{tabular}

*Adapted from Hall et al. [12]. Footrot-affected sheep $(n=38)$ were alternately randomized into two treatment groups and at 1-month intervals injected subcutaneously with $5 \mathrm{mg}$ of $\mathrm{Se}$ (FR-Se) or with 1-mL of saline solution (FRSal) for 15 months. A control group of 19 healthy sheep without FR received no injections. There were 19 sheep/group at 0 and 3 months, 18 to 19 sheep/ group at 6 months, and 9 to 14 sheep/group at 15 months.

a, b Medians with different superscripts within month are different $(P<0.05)$.

\section{Results}

Foot Lesions

Treatment with monthly Se injections accelerated recovery from FR as previously reported [12]. Footrot-affected ewes receiving Se had lower foot scores than FR-affected ewes receiving saline (overall $P=0.04$ ), with the primary differences being observed at $3(P=0.07)$ and $6(P=0.03)$ months after starting Se supplementation (Figure 1a).

To assess the effect of WB-Se status on subsequent foot scores, FR-affected ewes were stratified by WB-Se concentration (cutoff value: $250 \mathrm{ng} / \mathrm{mL}$ ) at 3 months, prior to receiving the fourth monthly Se injection. Footrot-affected ewes with WB-Se concentrations of at least $250 \mathrm{ng} / \mathrm{mL}$ (FR-High Se) had lower foot scores (overall $P=0.02)$ than FR-affected sheep with WB-Se concentrations below $250 \mathrm{ng} / \mathrm{mL}$ (FR-Low Se; Figure 1b). Greater WB-Se concentrations after 3 months of Se treatment predicted future recovery from FR. Foot scores were decreased at 15 months compared to 3 months after starting the study in FR-High Se ewes $(P=0.04)$ and were similar to control sheep, whereas foot scores did not change $(P=0.68)$ and remained high in FR-Low Se ewes (Figure 1b). As a result, the primary differences for ewes stratified by WB-Se status were observed $9(P=$ $0.08)$ and $15(P=0.05)$ months after starting $\mathrm{Se}$ treatment.

\section{Cell-mediated immunity as measured by the delayed-type} hypersensitivity skin test with KLH

Sheep affected with FR had less of a DTH response than healthy sheep, as measured by ear thickness (overall $P=$ 0.006; Figure 2a), ear wheal diameter (overall $P=0.02$; Figure $2 \mathrm{~b}$ ), and body wheal diameter (overall $P=0.04$; Figure 2c). The location of the test site was important for assessing the duration of the DTH response; the DTH response decreased quickest for ear wheal diameter (Figure 2b). Monthly Se injections improved part of the DTH response in FR-affected sheep. Whereas ear thickness decreased from 24 to $96 \mathrm{~h}$ in healthy sheep and FR-Sal sheep, no significant change in ear thickness was observed in FR-Se treated sheep (Figure 2a). As a result, FR-Se sheep had a greater ear thickness than FRSal sheep at $96 \mathrm{~h}$ after KLH challenge $(P=0.04)$ and a similar ear thickness compared with healthy sheep (Figure $2 \mathrm{a})$.

Footrot-affected sheep with higher WB-Se concentrations ( $\geq 250 \mathrm{ng} / \mathrm{mL}$ ) had more intense DTH responses than FR-affected sheep with lower WB-Se concentrations $(<250 \mathrm{ng} / \mathrm{mL})$ as measured by ear thickness $(P=$ 0.04; Figure 2d). Ear wheal diameter tended to be greater in FR-High Se sheep compared to FR-Low Se sheep after $72 \mathrm{~h}(P=0.10)$ and $96 \mathrm{~h}(P=0.13$; Figure $2 \mathrm{e})$, whereas Se status only numerically improved the DTH response for body wheal diameter (Figure 2f). 


\section{Se-Treatment}

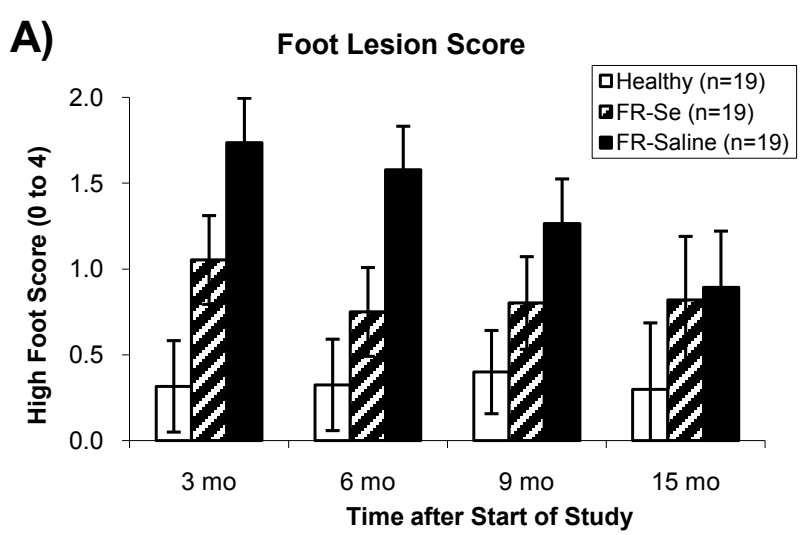

$\underline{\text { Se-Status }}$

B) Foot Lesion Score

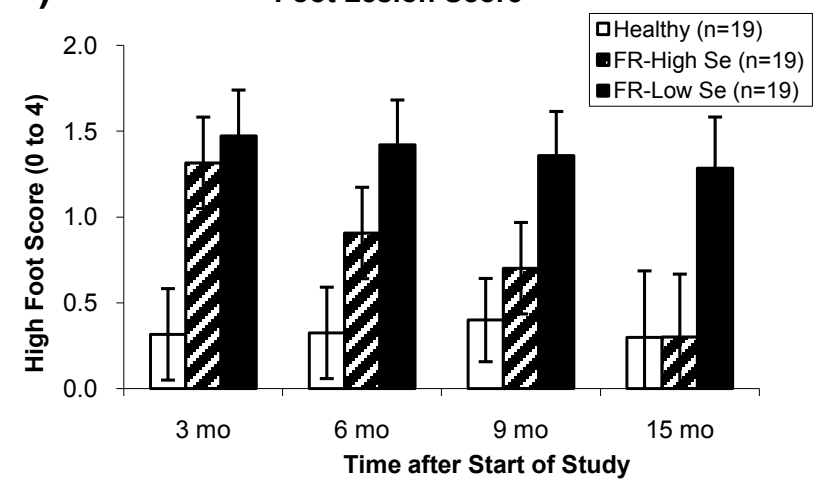

Figure 1 Foot lesion scores in healthy and footrot-affected sheep treated with selenium or saline. Footrot-affected (FR) sheep receiving monthly Se injections, had A) lower foot lesion scores (overall: $P=0.04)$, and in particular at $3(P=0.07)$ and $6(P=0.03)$ months after the start of the study. B) After stratifying FR-affected sheep by whole-blood Se (WB-Se) status at 3 months after the start of the study (WB-Se cut-off: 250 $\mathrm{ng} / \mathrm{mL}$ ), sheep with WB-Se concentrations above $250 \mathrm{ng} / \mathrm{mL}$ (FR-High Se) had decreased foot lesion scores by the end of the study $(P=0.04)$, whereas foot lesion scores did not change $(P=0.68)$ in sheep with WB-Se concentrations below $250 \mathrm{ng} / \mathrm{mL}$ (FR-Low Se). As a result, foot lesion scores were lower in FR-High Se sheep compared with FR-Low Se sheep (overall $P=0.02$ ).

\section{Humoral immunity as measured by the KLH antibody titer}

Sheep affected with FR had lower KLH antibody titers 2 and 4 weeks after KLH immunization compared with healthy sheep (overall $P=0.02$ ), which was not altered by Se treatment (Figure 3a). Selenium status tended to be associated with a greater KLH antibody titer (Figure 3b). After stratification by Se status, FR-Low Se sheep had lower KLH antibody titers compared with healthy control sheep $(P=0.02)$, whereas FR-High Se sheep had intermediary values $(P=0.09$ versus healthy sheep and $P=0.48$ versus FR-Low Se sheep; Figure $3 \mathrm{~b}$ ).

\section{Innate immunity measurements}

Sheep affected with FR, regardless of Se treatment had smaller ear wheal diameters compared with healthy sheep $30 \mathrm{~min}$ after KLH challenge ( $P=0.05$; Figure $4 \mathrm{a})$. Monthly Se injections decreased the $30 \mathrm{~min}$ response to histamine $(P=0.02$; Figure $4 \mathrm{a})$. Sheep with FR-High Se status at the time of the DTH assay had a decreased response to histamine at $30 \mathrm{~min}$ compared with FR-Low Se sheep $(P=0.02$; Figure $4 b)$.

Sheep affected with FR had a lower percent neutrophil bacterial killing of Lactococcus lactis compared with healthy sheep $(P=0.04)$, which was not altered by Se treatment $(P=0.36$; Figure $4 \mathrm{c})$. Whole blood-Se status was not associated with altered neutrophil bacterial killing ability $(P=0.26$; Figure $4 d)$.

Sheep affected with FR had lower mRNA concentrations of IL-8R compared with healthy sheep $(P=0.02)$, which were not altered by Se treatment $(P=0.24$; Figure $4 \mathrm{e})$. Relative abundance of L-selectin mRNA concentrations were not affected by FR-status $(P=0.88)$ or Se treatment $(P=0.56$; Figure $4 \mathrm{e})$. Whole blood-Se status in sheep with FR was not associated with altered mRNA concentrations of IL-8R $(P=0.32)$, but tended to be associated with increased mRNA concentrations of L-selectin in FR-High Se sheep $(P=0.07$; Figure $4 f)$.

\section{Discussion}

We reported previously that sheep affected with FR have lower WB-Se concentrations and that parenteral Se-supplementation in conjunction with routine control practices accelerates recovery from FR [12]. To determine whether Se acts as an immunonutrient and improves immune function in FR-affected sheep, we examined the effect of FR, Se treatment, and WB-Se status on measures of CMI, humoral immunity, and innate immunity. Our primary finding is that immune responses to a novel protein $(\mathrm{KLH})$ are attenuated in FR-affected sheep with lower WB-Se status. Furthermore, the DTH and antibody titer responses to a novel protein were improved, in part, by Se treatment and high WB-Se status, supporting our hypothesis that Se acts as an immunonutrient in FR-affected sheep. Neutrophil function was suppressed by FR, but was not changed by Se supplementation or WB-Se status.

The purpose of this follow-up study was to investigate the mechanisms by which Se facilitates recovery from FR. The immune system has two functional divisions: innate and adaptive immunity. Both divisions involve various blood-borne factors (e.g., complement, antibodies, and cytokines) and cells (e.g., neutrophils, lymphocytes, and macrophages). There is large individual 


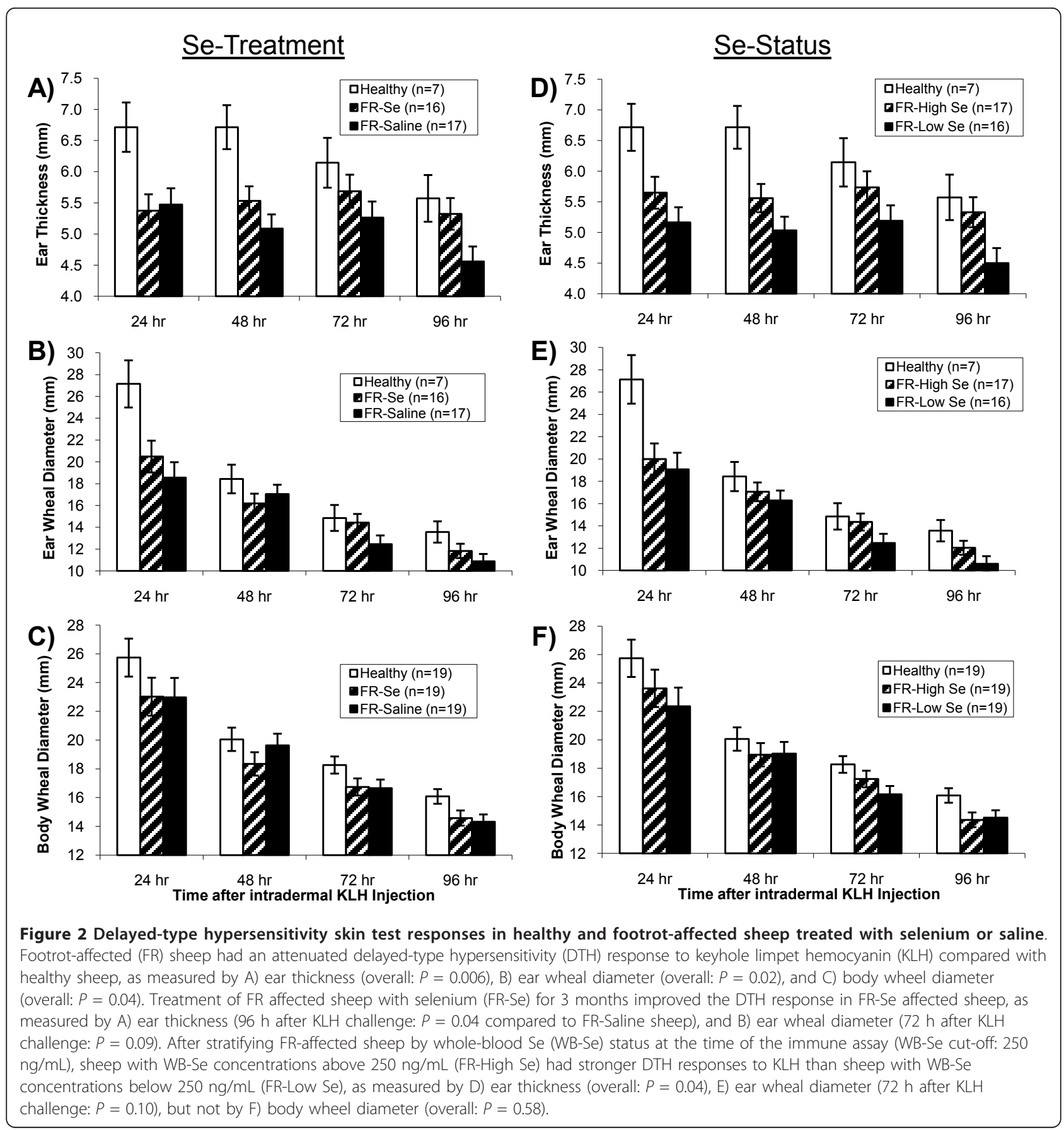

variation in immune function even among healthy animals. For example, differences in genetics, age, gender, levels of exercise, diet, stress, infectious disease history, vaccination status, and early life experiences are important contributors to this observed variation [17]. Thus, demonstrating an improvement in immune function with Se supplementation is challenging.

Tests used to assess adaptive immunity include the DTH test, which is also known as a type IV hypersensitivity reaction. This test provides a general measure of CMI. Professional antigen presenting cells, e.g., dendritic cells, present antigen to $\mathrm{T}$ lymphocytes. This results in antigenspecific activation of $\mathrm{T}$ lymphocytes in local tissues. Inflammatory cytokines produced by these stimulated $\mathrm{T}$ lymphocytes cause other mononuclear cells (lymphocytes and macrophages) to migrate to the area and proliferate. To perform this test, foreign antigen is injected under the epidermis of the skin. The immune system responds to 

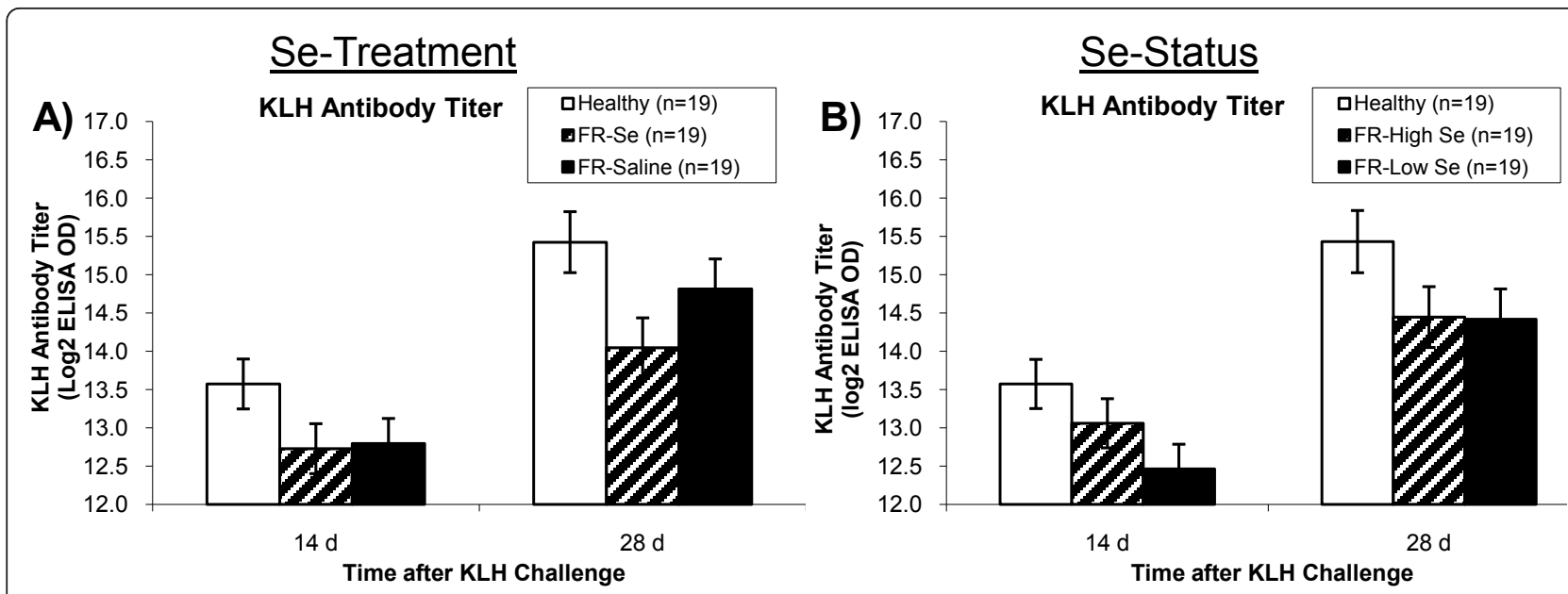

Figure 3 Antibody titers to keyhole limpet hemocyanin in healthy and footrot-affected sheep treated with selenium or saline. Footrotaffected (FR) sheep, regardless of Se treatment, had A) lower keyhole limpet hemocyanin (KLH) antibody titers 2 and 4 weeks after the second $\mathrm{KLH}$ immunization compared with healthy sheep (overall: $P=0.02$ ). B) After stratifying FR-affected sheep by whole-blood Se (WB-Se) status at the time of the immune assay (WB-Se cut-off: $250 \mathrm{ng} / \mathrm{mL}$ ), sheep with WB-Se concentrations below $250 \mathrm{ng} / \mathrm{mL}$ (FR-Low Se) had lower KLH antibody titers compared with healthy sheep (overall: $P=0.02$ ), whereas sheep with Se concentrations above $250 \mathrm{ng} / \mathrm{mL}$ (FR-High Se) had intermediate values (overall: $P=0.09$ versus healthy sheep; overall: $P=0.48$ versus FR-Low Se sheep).

this antigen by producing a small raised wheal that can be measured 24 to $96 \mathrm{~h}$ after injection. The larger the wheal, the greater is the CMI response.

In our study, healthy control sheep demonstrated an enhanced CMI response to a novel protein (KLH) compared with FR-affected sheep based on the DTH test. Results were more definitive for the ear tip compared with two wool-free sites on the ventro-lateral abdomen, likely because higher tissue compliance allowed a more diffuse DTH reaction on the abdomen. For this reason, the latter may not be as useful of a test location as the ear tip for this assay in sheep. Both ear thickness and ear wheal diameter were similarly affected, although the DTH response resolved faster over time for ear wheal diameter. The DTH response in healthy sheep receded from 24 to $96 \mathrm{~h}$. Although ear thickness was suppressed at $24 \mathrm{~h}$ in FR ewes compared to healthy controls, there was no change across time in FR-Se treated sheep. Thus, by 96 h FR-Se sheep had a greater ear thickness than FR-Sal sheep and a similar ear thickness compared with healthy control sheep. Similarly, FR-affected sheep with higher WB-Se concentrations had a more intense DTH response than FR-affected sheep with lower WBSe concentrations. Our results suggest an attenuated Tlymphocyte response in FR-affected sheep, which could be the result of decreased activation, migration, proliferation, or a combination of these, and which may be improved, in part, by Se treatment. An enhanced DTH response after Se supplementation was also shown by Lacetera et al. [18]. In their study, ewes given a single 5 $\mathrm{mg}$ Se injection $30 \mathrm{~d}$ prior to lambing had a greater
DTH response to intradermal phytohaemagglutinin (PHA) injection at $6 \mathrm{~h}$ than ewes not treated with Se. Lambs born to Se-treated ewes had a greater DTH response to PHA $24 \mathrm{~h}$ after injection. In this study as well as ours, Se was supplemented to Se-adequate sheep. Methodology differences with injection site (ear vs. neck), antigen (KLH vs. PHA), response time (days vs. hours), and measurement technique (wheal reaction vs. skin thickness) likely account for differences between the studies.

Measuring an antibody titer in response to sensitization/immunization is another test to assess the adaptive (humoral) immune response. The animal is injected with a novel protein (e.g., KLH) that elicits an immune response. Following sensitization, antibody titers to KLH can be measured. Our results showed that FR disease was associated with lower KLH antibody titers 2 and 4 weeks after KLH immunization compared with healthy sheep, suggesting a lower antibody titer to a novel protein in FR-affected sheep. Stratification by WB-Se status showed that sheep with FR-High Se had KLH antibody titers more similar to healthy control sheep 14 days after the second immunization. There was no difference in antibody titers between FR-Se and FR-Sal treated ewes at 28 days, suggesting that titers may rise more rapidly in FR-Se treated ewes, similar to what we have shown in cattle [19]. Our results suggest that Se may improve antibody production in response to a novel protein in FR-affected sheep. It would be interesting to look at earlier titers in future studies, for example at 7 days after the second immunization. 


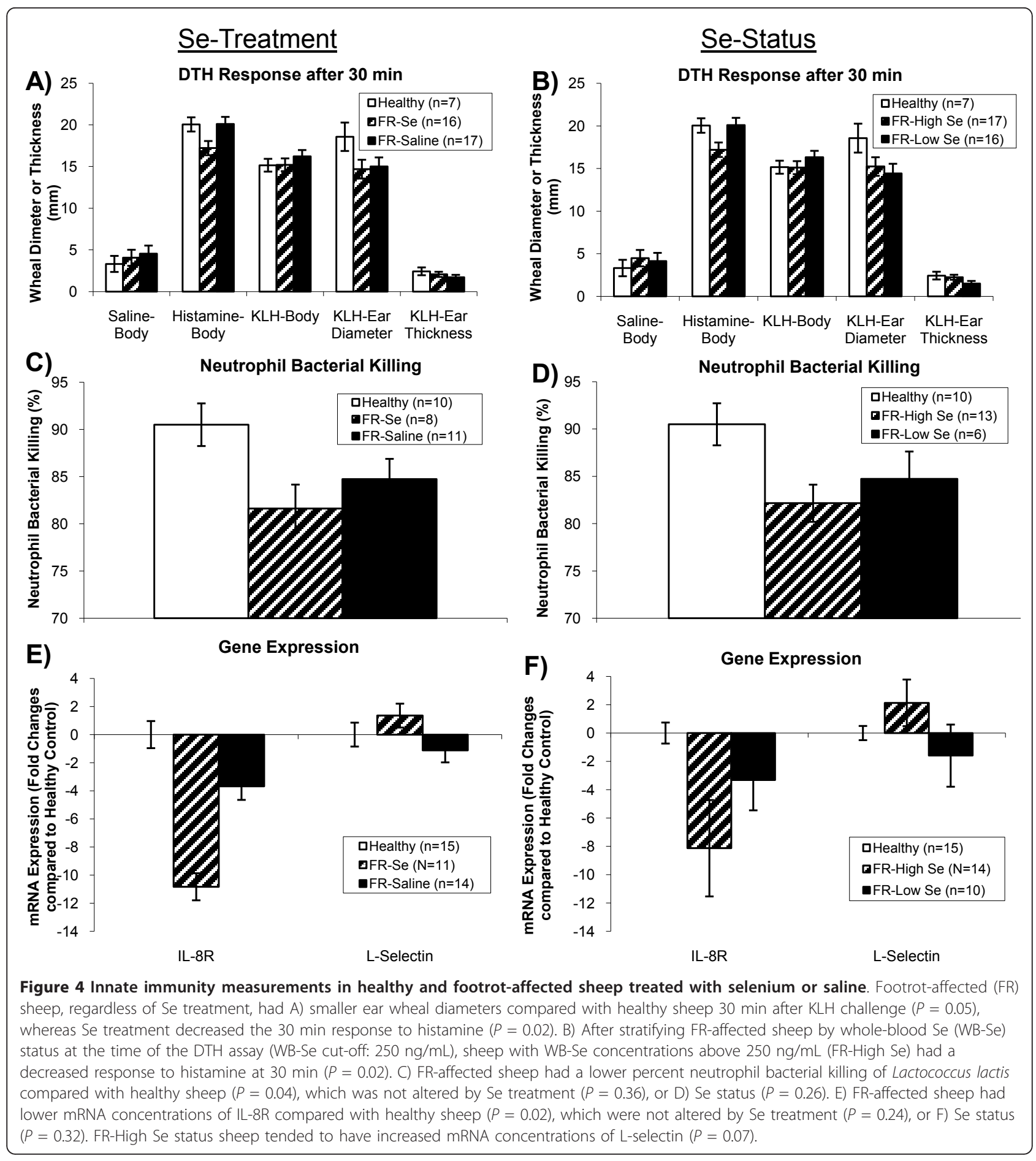

Sheep affected with FR, regardless of Se treatment had smaller ear wheal diameters compared with healthy sheep 30 min after KLH challenge. This is consistent with a reduction in the type I hypersensitivity reaction normally induced by histamine and inflammatory cytokines. The KLH stimulates inflammatory cytokine production. Bacterial infection may cause immunosuppression of Type I hypersensitivity by affecting the release of histamine, or virulence factors such as leukotoxin, endotoxin, haemolysin, haemagglutinin and adhesin that are used to overcome the host's defense mechanisms when infection is established may also suppresses the immune response.

Selenium treatment decreased the 30 min skin-test response to histamine in FR-affected sheep. Histamine 
normally increases capillary permeability and relaxes vascular smooth muscle, allowing edema fluid accumulation. Influx of proinflammatory cytokines triggers production of reactive oxygen species (ROS). When produced in excess, ROS are important mediators of cell and tissue injury. Because Se is involved in redox reactions, and immune activation is usually associated with increased production of ROS by cells of the immune system, higher Se may help suppress tissue damage caused by ROS (reviewed in Murr et al. [20]). As a component of the glutathione peroxidase family of enzymes, Se contributes to the reduction of hydroperoxides in cells. Glutathione peroxidase reduces ROS to less reactive metabolites, decreasing oxidant stress. We suggest that Se suppressed oxidative stress and attenuated the early skin-test reaction at $30 \mathrm{~min}$. Thus, Se may protect from type I hypersensitivity reactions, involving IgE antibody triggering of mast cells and oxidative insult, by preventing lipid hydroperoxide accumulation. On the other hand, Se enhanced the type IV hypersensitivity reaction at $96 \mathrm{~h}$.

Neutrophils are the most numerous and important cellular component of innate immunity. Their primary functions are phagocytosis and destruction of microorganisms. They serve as the body's first line of defense against invading microorganisms. Phagocytosed bacteria are rapidly killed by proteolytic enzymes (e.g., myeloperoxidase), antimicrobial proteins, and ROS when membrane-bound granules fuse with phagocytic vesicles. In addition to phagocytosis, bacterial killing occurs via neutrophil extracellular traps (NETs) [21-23]. Upon activation, neutrophils release extracellular fibers called NETS, which form a meshwork that kills bacteria extracellularly without the need for phagocytosis. NETs are made up of DNA, histones, and granule proteins such as elastase. Both Gram-positive and Gram-negative bacteria are killed, which suggests that NETs can kill a wide range of pathogens. These NETs serve as a physical barrier, which prevents the spread of bacteria.

To assess innate immunity of neutrophils, a biologic assay was performed using Lactococcus lactis and measuring percent bacterial killing. Neutrophils from healthy control sheep demonstrated higher percent bacterial killing compared with neutrophils from FRaffected sheep, regardless of 15 months of Se supplementation. Even when FR-affected sheep were stratified by WB-Se status, neutrophil bacterial killing ability was not altered. Our results suggest that FR-affected sheep have reduced neutrophil bacterial killing ability, which cannot be improved by Se supplementation or high WB-Se status. It has been reported previously that neutrophils of Se-deficient cattle have reduced ability to kill phagocytosed bacteria [24,25]. Although acute infections have been shown to decrease serum-Se levels [26], sheep in the current study were Se-adequate. It is possible that supranutritional Se does not further improve neutrophil bacterial killing ability or that the disease state inhibits or prevents modulation of neutrophil bacterial killing ability.

Measuring the relative abundance of mRNA specific for neutrophil migration activity (L-selectin and IL-8R) by RT-qPCR is another method for assessing innate immunity. To protect against invading pathogens, neutrophils migrate to infected sites. Neutrophils roll along walls of blood vessels by the coordinated formation and breakage of selectin-carbohydrate chemical bonds. Lselectin is a cell surface glycoprotein that is constitutively expressed on the surface of most leucocytes [27]. L-selectin is important for the binding and subsequent rolling of leucocytes along endothelial walls, facilitating migration into secondary lymphoid organs (e.g., naive $\mathrm{T}$ cells) and into sites of inflammation (e.g., neutrophils) [27]. Chemokines such as IL-8 and its receptor control the interaction of neutrophils with the epithelial cell barrier. IL-8 is recognized mainly for its ability to induce neutrophil migration, but it also increases cytokine production, enhances phagocytosis and ROS generation, and regulates cell survival [28-30]. In our study, we found that sheep affected with FR had lower concentrations of IL-8R mRNA compared with healthy sheep, and Se treatment had no effect. Our results suggest that attenuated IL-8R gene expression may play a role in reducing bacterial killing ability in FR-affected sheep; IL-8R gene expression, however, may not be responsive to Se treatment. The relative abundance of $\mathrm{L}$-selectin mRNA was not affected by FR-status, however, mRNA concentrations tended to be higher in FR-High Se sheep, suggesting that L-selectin is a potential molecular target of Se treatment.

In conclusion, our goal was to determine if supplementing Se at concentrations above those currently recommended for sheep (supranutritional) can modulate the immune response in a way that reduces severity and/ or improves recovery from a disease process. We reported previously that parenteral Se supplementation in conjunction with routine control practices resulted in higher WB-Se concentrations and more rapid improvement of foot lesions [12]. In this study, we found that neutrophil function and the DTH and antibody titer responses to a novel protein $(\mathrm{KLH})$ were attenuated in FR-affected sheep. The DTH and antibody titer responses to a novel protein were improved, in part, by Se treatment and WB-Se status, suggesting that FR in sheep is associated with reduced lymphocyte function, which may be partly restored by improving WB-Se status ( $\geq 250 \mathrm{ng} /$ $\mathrm{mL}$ ). Additional experiments are needed to determine the best source, route of administration, and dose of Se to optimize immune function in sheep with FR. 


\section{Abbreviations}

CFU: colony forming units; CMI: cell-mediated immunity; DTH: delayed-type hypersensitivity; FR: foot rot; FR-Se: foot-rot ewes receiving selenium injections; FR-Sal: foot-rot ewes receiving saline injections; KLH: keyhole limpet hemocyanin; Se: selenium; T-PBS: Tween-PBS; ABTS: 2,2'-Azino-bis (3ethylbenzthiazoline-6-sulfonic acid); HBSS: Hank's balanced saline solution; MOI: multiplicity of infection; PHA: phytohaemagglutinin; RBC: red blood cells; ROS: reactive oxygen species; RPL-19: ribosomal protein large subunit family member-19; WB: whole blood.

\section{Acknowledgements}

The work presented in this study was performed at the Department of Biomedical Sciences, College of Veterinary Medicine, Oregon State University, Corvallis, OR, 97331-4802, USA, and supported in part by Animal Health and Disease Project Formula Funds, Oregon State University, Corvallis, OR 973312219. The authors thank Joe Sonka, who passed away during the study, and his family for providing the sheep and allowing us to perform a long-term clinical trial on their ranch.

\section{Author details}

'Department of Biomedical Sciences, College of Veterinary Medicine, Oregon State University, Corvallis, OR 97331-4802, USA. ${ }^{2}$ Department of Animal Sciences, College of Agriculture, Oregon State University, Corvallis, OR 97331 4802, USA. ${ }^{3}$ Department of Clinical Sciences, College of Veterinary Medicine, Oregon State University, Corvallis, OR 97331-4802, USA. ${ }^{4}$ Department of Veterinary \& Biomedical Sciences, College of Agricultural Sciences, Pennsylvania State University, University Park, PA 16802, USA. ${ }^{5}$ Linus Pauling Institute, Oregon State University, Corvallis, OR 97331-6512, USA.

\section{Authors' contributions}

JAH conceived the study, participated in its design, coordination, and field work, and drafted the manuscript. RLS participated in the laboratory work and contributed to writing the manuscript. RMC, WRV, YW, and BVS participated in the laboratory work. DPB, KNT, NEF participated in the field work and the laboratory work. RJVS and GB participated in the design of the study and performed the statistical analysis. All authors read and approved the final version of the manuscript.

\section{Competing interests}

This manuscript, in whole or in part, has not been published elsewhere, and has been read and approved by all authors. Sources of extra institutional funding or support have been acknowledged. There are no financial or personal conflicts of interest. The authors represent and warrant that our part of the work as submitted will in no way violate any copyright, or any other right.

Received: 27 April 2011 Accepted: 6 September 2011 Published: 6 September 2011

\section{References}

1. Egerton JR, Roberts DS, Parsonson IM: The aetiology and pathogenesis of ovine foot-rot. I. A histological study of the bacterial invasion. $J$ Comp Path 1969, 79:207-215.

2. Roberts DS, Egerton JR: The aetiology and pathogenesis of ovine footrot. II. The pathogenic association of Fusiformis nodosus and F. necrophorus. J Comp Path 1969, 79:217-227.

3. Bennett G, Hickford J, Sedcole R, Zhou H: Dichelobacter nodosus, Fusobacterium necrophorum and the epidemiology of footrot. Anaerobe 2009, 15:173-176.

4. Elleman TC, Hoyne PA, Emery DL, Stewart DJ, Clark BL: Isolation of the encoding pilin of Bacteroides nodosus (strain 198), the causal organism of ovine footrot. FEBS Lett 1984, 173:103-107.

5. Green LE, George TR: Assessment of current knowledge of footrot in sheep with particular reference to Dichelobacter nodosus and implications for elimination or control strategies for sheep in Great Britain. Vet J 2008, 175:173-180.

6. Mitchell R: Footrot Eradication in Western Australia Published by the Department of Agriculture Western Australia, Scott Print; 2003.

7. Kaler J, Daniels SL, Wright JL, Green LE: Randomized clinical trial of longacting oxytetracycline, foot trimming, and flunixine meglumine on time to recovery in sheep with footrot. J Vet Intern Med 2010, 24:420-425.
8. Raadsma HW, O'Meara TJ, Egerton JR, Lehrback PR, Schwartzkoff CL: Protective antibody titres and antigenic competition in multivalent Dichelobacter nodosus fimbrial vaccines using characterised rDNA antigens. Vet Immunol Immunopath 1994, 40:253-274.

9. Escayg AP, Hickford JG, Bullock DW: Association between alleles of the ovine major histocompatibility complex and resistance to footrot. Res Vet Science 1997, 63:283-287.

10. Egerton JR, Roberts DS: Vaccination against ovine foot-rot. J Comp Pathol 1971, 81:179-185.

11. Schwartzkoff CL, Egerton JR, Stewart DJ, Lehrbach PR, Elleman TC, Hoyne PA: The effects of antigenic competition on the efficacy of multivalent footrot vaccines. Austr Vet J 1993, 70:123-126.

12. Hall JA, Bailey DP, Thonstad KN, Van Saun RJ: Effect of parenteral selenium supplementation to sheep on prevalence and recovery from footrot. J Vet Intern Med 2009, 23:352-358.

13. Kiremidjian-Schumacher L, Stotzky G: Selenium and immune responses. Environ Res 1987, 42:277-303.

14. Wander RC, Hall JA, Gradin JL, Du SH, Jewell DE: The ratio of dietary (n-6) to $(n-3)$ fatty acids influences immune system function, eicosanoid metabolism, lipid peroxidation, and vitamin E status in aged dogs. J Nutr 1997, 127:1198-1205.

15. Wang Y, Puntenney S, Burton J, Forsberg N: Ability of a commercial feed additive to modulate expression of innate immunity in sheep immunosuppressed with dexamethasone. Animal 2007, 1:945-951.

16. Pfaffl MW: Quantification strategies in real-time PCR. In $A-Z$ of quantitative $P C R$. Edited by: Bustin SA. La Jolla, CA: International University Line; 2004:89-120.

17. Finch JM, Turner RJ: Effects of selenium and vitamin $E$ on the immune responses of domestic animals. Res Vet Sci 1996, 60:97-106.

18. Lacetera N, Bernabucci U, Ronchi B, Nardone A: The effects of injectable sodium selenite on immune function and milk production in Sardinian sheep receiving adequate dietary selenium. Vet Res 1999, 30:363-370,

19. Hall JA, Harwell AM, Van Saun RJ, Vorachek WR, Stewart WC, Galbraith ML, Hooper KJ, Hunter JK, Mosher WD, Pirelli GJ: Agronomic biofortification with selenium: Effects on whole blood selenium and humoral immunity in beef cattle. Anim Feed Sci Technol 2011, 164:184-190.

20. Murr C, Talasz H, Artner-Dworzak E, Schroecksnadel K, Fiegl M, Fuchs D, Denz HA: Inverse association between serum selenium concentrations and parameters of immune activation in patients with cardiac disorders. Clin Chem Lab Med 2007, 45:1224-1228.

21. Brinkmann V, Reichard U, Goosmann C, Faule B, Uhlemann Y, Weiss DS, Weinrauch $Y$, Zychlinshy A: Neutrophil extracellular traps kill bacteria. Science 2004, 303:1532-1535.

22. Lee WL, Grinstein S: The tangled webs that neutrophils weave. Science 2004, 303:1477-1478.

23. Buchanan JT, Simpson AJ, Aziz RK, Liu GY, Kristian SA, Kotb M, Feramisco J, Nizet V: DNase expression allows the pathogen group A Streptococcus to escape killing in neutrophil extracellular traps. Curr Biol 2006, 16:396-400.

24. Boyne R, Arthur JR: Alterations of neutrophil function in seleniumdeficient cattle. J Comp Pathol 1979, 89:151-158.

25. Gyang EO, Stevens JB, Olson WG, Tsitsamis SD, Usenik EA: Effects of seleniumvitamin $\mathrm{E}$ injection on bovine polymorphonucleated leukocytes phagocytosis and killing of Staphylococcus aureus. Am J Vet Res 1984, 45:175-177.

26. Sammalkorpi K, Valtonen V, Alfthan G, Aro A, Huttunen J: Serum selenium in acute infections. Infection 1988, 16:222-224.

27. Waddell TK, Fialkow L, Chan CK, Kishimoto TK, Downey GP: Signaling functions of L-selectin. Enhancement of tyrosine phosphorylation and activation of MAP kinase. J Biol Chem 1995, 270:15403-15411.

28. Kettritz R, Gaido ML, Haller H, Luft FC, Jennette CJ, Falk RJ: Interleukin-8 delays spontaneous and tumor necrosis factor-alpha-mediated apoptosis of human neutrophils. Kidney Int 1998, 53:84-91.

29. Mitchell GB, Albright BN, Caswell JL: Effect of interleukin-8 and granulocyte colony-stimulating factor on priming and activation of bovine neutrophils. Infect Immun 2003, 71:1643-1649.

30. Jozsef $L$, Khreiss T, El Kebir D, Filep JG: Activation of TLR-9 induces IL-8 secretion through peroxynitrite signaling in human neutrophils. Immunol 2006, 176:1195-1202.

doi:10.1186/1297-9716-42-99

Cite this article as: Hall et al:. Higher whole-blood selenium is associated with improved immune responses in footrot-affected sheep. Veterinary Research 2011 42:99. 